\title{
Range Extension and Species Confirmation of Rhyneptesicus Nasutus (Sind Serotine Bat) (Mammalia: Chiroptera) From Bajaur Agency, FATA, Pakistan
}

Muhammad Idnan ( $\square$ muhammad.idnan@uvas.edu.pk)

University of Central Punjab https://orcid.org/0000-0002-6583-1783

\section{Sajid Mansoor}

Central University of Punjab

Muhammad Babar Khawar

University of Central Punjab

Arshad Javid

University of Veterinary and Animal Sciences

Ali Hussain

University of Veterinary and Animal Sciences

Muhammad Imran

University of Veterinary and Animal Sciences

Arif Ullah

University of Veterinary and Animal Sciences

\section{Research Article}

Keywords: Chiroptera, cytochrome b, phylogenetic analysis, mitochondrial, Eptesicus.

Posted Date: September 20th, 2021

DOI: https://doi.org/10.21203/rs.3.rs-848167/v1

License: (c) (1) This work is licensed under a Creative Commons Attribution 4.0 International License. Read Full License 


\section{Abstract}

The lack of morphological differentiation among chiropteran species and cryptic speciation impedes species identification. So, DNA-based approaches boost species identification and are increasing biological diversity. Rhyneptesicus nasutus (Sind Serotine Bat) is a rarely distributed and poorly studied species in Pakistan. This study explores the range extension of Sind bat within the territorial limits of Pakistan from Sind and Baluchistan to Federally Administered Areas (FATA) of Pakistan. No molecular record exists for the species in Pakistan. In the present study, we for the first time present the data to confirm the species identification by genetic marker (cytochrome b) along with morphometric analysis of Rhyneptesicus nasutus from Pakistan. The neighbor-joining tree based on Kimura-2 parameters was created to infer the phylogenetic analyses. We sequenced the cytochrome $b$ gene segment and conducted a phylogenetic analysis with previously published data from other countries. Sequences from Pakistan made a clade with Iranian Rhyneptesicus nasutus species suggesting a common ancestry. Various morphometric parameters (mean values) were measured like Head and Body length (44.3mm), Tail length $(43.4 \mathrm{~mm})$, Hindfoot length $(8.3 \mathrm{~mm})$, Forearm length $(35.7 \mathrm{~mm})$, and Ear length $36 \mathrm{~mm}$ while 5 th Metacarpal Length, 4th Metacarpal Length, and 3rd Metacarpal Lengths were $33.2 \mathrm{~mm}, 34.7 \mathrm{~mm}, 35.3 \mathrm{~mm}$. Approaches based on DNA barcoding reveals high diversity of bat species in the study area. The data will enable researchers to build an improved evolutionary landscape of the Serotine bats from this region and subsequently reconstruct a detailed evolutionary history of the genus. Further research is required to test other molecular markers to support the findings of the current study in Pakistan.

\section{Introduction:}

More than 100 million different species inhabit our planet of which only a few, about 1.5 million have been characterized [1]. Bats comprise roughly $20 \%$ of the mammalian diversity with around 1400 species discovered worldwide [2]. Bats being the 2nd most diverse group of mammals are essential to the ecological health of any ecosystem, by playing a vital role not only in several predator-prey relationships but also in the dispersal of seeds, plant pollination, and nutrients distribution/recycling.

Moreover, bats have a great impact on humans as well where bats are involved with insects and pest management. Bats feast on a number of insects that damage crops and are serious forest pests. An analysis from a study of North American insectivore bats highlighted that a loss of bats in that region leads to an annual agricultural loss of more than $\$ 3.7$ billion. Bats are hunted for their bushmeat and medicine, are praised for their aesthetics (bat watching tourism), and are studied for educational and research purposes. However, it is of note that few species are themselves pests, impacting livestock and agriculture sector, damage buildings, and are potential reservoirs of many infectious agents $[3,4]$.

Bats are extremely biodiverse, however, due to the cryptic speciation, this component of biodiversity is usually neglected. Furthermore, the exact characterization of any species is imperative for conservative efforts to conserve their vital ecological role [5]. Recent advancements in better interpretation of molecular biology data (superior phylogenetic reconstructions) have paved the way for the identification 
of these cryptic species. Moreover, combining these techniques with modern approaches that explore "acoustic" has vastly expanded the number of the identified bat species. [6] [7].

Rhyneptesicus nasutus is present in Saudi Arabia, the Islamic Republic of Iran, Afghanistan, Iraq, Oman, Yemen, and Pakistan [8]. Interestingly, this species has probably never been abundant throughout its relatively restricted geographical range [9]. Furthermore, the species is rare and locally distributed in Pakistan where it has been reported from Kharan and Rajbar - Baluchistan, and Shikarpur - Sindh [10]. $R$. nasutus is known as the 'Sind Serotine' bat and its status is designated as "Least Concern" by IUCN [11].

Modern molecular techniques also suggest that in Southeast Asia the number of bat species is double the currently described species. In areas of high endemism and hotspots of biodiversity, the cryptic species are more prevalent as such areas are considered to have a high potential of speciation [12].Other than the cytochrome $b$ gene, 16S rRNA and 12S rRNA could also be used for species identification, but the cytochrome $b$ gene has been used for the last two decades for animal identification and differentiation among closely related taxa. Cytochrome $b$ gene shows a high polymorphism that is why it is used for species identification $[13,14]$.

Hence, the current study was designed for species identification, genetic differentiation, and phylogenetic analysis of Rhyneptesicus nasutus from Pakistan by using the mtDNA cytochrome $b$ region from chiropteran taxon, Bajaur Agency, FATA region of Pakistan.

\section{Materials And Methods:}

\section{Sampling}

The bat samples were captured from the FATA region, $32.6675^{\circ} \mathrm{N}, 69.8597^{\circ} \mathrm{E}$, comprising a total area of $27,220 \mathrm{~km}^{2}$ of Pakistan (Table $2 \&$ Fig. 3 ). The roost sites of the bat were found in cervices and holes in buildings and caves. The information about the roosts of the bats was also collected from the nomads. The mist nets of different categories and different lengths $(5 \mathrm{~m}, 8 \mathrm{~m}, 11 \mathrm{~m})$ were used for bats collections. The mist nets were applied mostly before the time of the evening. The nets were applied on water bodies and the narrow ways where the bats were more in number. The sampling was extending from June 2016 to August 2018. During the time frame of sampling, all the potential roosting sites were searched thoroughly to collect the sample.

\section{Sample Preservation \& Measurements}

During sampling 215 bats samples belonging to different genera (Genus Pipistrellus, Genus scotophillus, Genus Rhinopoma, Genus Rousettus, Genus Myotis, and Genus Rhinolophus) were captured. Samples belonging to Rhyneptesicus nasutus species were 06 . Various morphometric measurements were noted in table 1 . Some samples $(n=2)$ were preserved in $70 \%$ ethanol for molecular analysis. Bats were euthanized by placing a bat in an airtight zipper bag followed by the placement of an Isoflurane (3-5 $\mathrm{ml})$ 
soaked cotton ball in the bag. This was closed for 40 minutes and it was ensured that the bat was not alive. The comparative observational analyses were performed with Bates and Harrison $[9,15]$.

\section{DNA Extraction and Amplification of Cytochrome b Gene}

Genomic DNA was extracted from ethanol (70\%) preserved specimens (wing tissue i.e., $10 \mu \mathrm{g}$ ) at Post Graduate Lab, Institute of Biochemistry and Biotechnology (IBBt), University of Veterinary and Animal Sciences, Lahore, Pakistan, by standard phenol-chloroform extraction method [16]. Fragments of mtDNA were amplified using a set of primers described by Kocher 1989 forward primer 5CCATCCAACATCTCAGCATGATGAAA-3 and reverse primer 3-CCCTCAGAATGATATTTGTCCTCA-5 [17].

For PCR reaction a volume of $25 \mu \mathrm{L}$ was used as a reaction mixture under conditions: initial denaturation at $95 \mathrm{C}^{\circ}$ for 4 minutes, 30 -second denaturation at $94 \mathrm{C}^{\circ}$, annealing at $59 \mathrm{C}^{\circ}$ for 30 seconds, $72 \mathrm{C}^{\circ}$ for 30 seconds for extension, and $72 \mathrm{C}^{\circ}$ for 10 minutes for a final extension. PCR products were identified using $1.5 \%$ agarose gel and positive samples were purified by ethanol for DNA sequencing using ABI PRISM Genetic Analyzer 3130 xl. [18].

\section{Sequence Alignment and Analysis}

Chromas software was used to analyze Cytochrome b gene sequences [19], BLASTn software available on NCBI was used to align the sequences of cytochrome $b$ for species confirmation by molecular analysis. Single Nucleotide Polymorphisms (SNPs) were detected from aligned sequences and consensus sequences, and haplotypes were constructed. For molecular phylogenetic analysis, MEGA X software was used [20]. Newly obtained DNA sequences were submitted to GenBank for Accession numbers MT674673 and MW842644.

\section{Results:}

The main objective of the study was to explore the bat diversity in the study region of FATA, Pakistan, and use the cytochrome $b$ gene as a marker for species confirmation. Bats have cryptic speciation so morphological discrimination makes the taxonomic identification a difficult process. A small fragment of wing tissue yielded enough DNA and subsequently for molecular studies. PCR amplification of cytochrome $b$ gene by specific primers produced a single amplicon with $1 \%$ agarose gel. These PCR products of $R$. nasutus from Bajaur Agency, FATA, Pakistan, were got sequenced. These sequences were submitted to NCBI GenBank for accession numbers MT674673 and MW842644. On NCBI, the query sequences were aligned and compared with already published sequences of Rhyneptesicus species by BLASTn.

During the study, DNA sequences of chiropteran species representing Rhyneptesicus (formally known as Eptesicus) genera and the Vespertilionidae family were obtained. These DNA sequences have shown reliable and clear species identifications. Recently, DNA barcoding studies of Asian bats have been carried out and sequences of related species were available at NCBI. Closely related DNA sequences of 
cytochrome b were retrieved from public databases in blast searches. The neighbor-joining tree based on Kimura 2-parameter distance is shown in Fig. 2, where the query sequences are making a clade with Iranian Rhyneptesicus species, while the species from other regions like Oman, Yemen, China, Germany and Patagonia are not as close to Rhyneptesicus species reported from Pakistan. It suggests that these Rhyneptesicus species have evolved independently from the Iranian and Pakistani species.

The sequence results of the query sample were run in BLASTn, the percentage identity was $95.13 \%$ with Rhyneptesicus nasutus (FJ841981) and $100 \%$ query coverage, and this specimen is reported from Dehbarez, Hormozgan, Iran. Against our query sequence, gene sequences were retrieved from GenBank, used in subsequent phylogenetic analyses. Ambiguous sequences were trimmed. MEGA X was used for phylogenetic analysis by the Neighbor-joining method with Bootstrap values of 500 replicated. A common vampire bat (Desmodus rotundus) was used as an outgroup (Fig. 2). The accession number assigned by GenBank are MT674673 and MW842644 for Rhyneptesicus nasutus species from Pakistan reported by the current study in range extension and molecular confirmation by cytochrome $b$ gene.

Phylogenetic divergence is shown in Table 3 among Rhyneptesicus species from different regions of the world. The genetic divergence ( $p$ distance) among various Rhyneptesicus species reported from various regions of the world shows a minimum value of $0.000-0.087$. The $p$ distance value among the Pakistani Rhyneptesicus species and others published from various parts of the world showed genetic differentiation among them suggesting that they have evolved independently from one another.

Rhyneptesicus have a relatively long tail which is subequal to the head and body length. Forearm length averages $36.1 \mathrm{~mm}(35.4-36.9 \mathrm{~mm})$. The muzzle is broad and flat with prominent nearly naked pararhinal glandular swellings. The ears are small with narrowly rounded tips: the tragus of each is well developed. About half the height of the pinna. The pelage is buffy brown on the dorsal surface and paler on the ventral surface. The hair tips and bases are uniformly colored. The interfemoral and wing membranes ears and naked areas of the face are mid-brown, distinctly darker than the pelage (Table 1).

The skull is smaller than that of $E$. bottae with an average condylo-canine length of $12.0 \mathrm{~mm}(11.7-12.2$ $\mathrm{mm}$ ). The braincase is relatively small and flattened in lateral view as compared to that of Eptesicus bottae. The sagittal crest is absent, and the lambdoid crests are low but distinct. The slightly convex supraoccipital forms the most posterior part of the skull. The postorbital constriction is narrow, and the supraorbital ridges are well developed. The zygomatic arches are delicate and without dorsal projections: they are widely flared anteriorly and posteriorly. The palate is short and broad. The tympanic bullae are relatively large and exceed the breadth of the basioccipital. The coronoid process of each half mandible does not greatly exceed the condyle in height: in consequence the posterior border of the coronoid declines more gently than that of Eptesicus bottae.

Upper tooth row length $\left(\mathrm{c}-\mathrm{m}^{3}\right)$ averages $4.6 \mathrm{~mm}(4.4-4.8 \mathrm{~mm})$. The first upper incisor $\left(\mathrm{i}^{2}\right)$ is without a secondary cusp. The second incisor $\left(i^{3}\right)$ is relatively well developed, attaining half the height of $i^{2}$. The upper premolar $\left(\mathrm{pm}^{4}\right)$ is relatively small; its crown area slightly exceeds half that of $\mathrm{m}^{1}$; in Eptesicus 
bottae, it is more than three-quarters, $\mathrm{m}^{3}$ is about half the crown area of $\mathrm{m}^{2}$ and with three well-developed commissures. The first lower premolar $\left(\mathrm{pm}_{2}\right)$ is relatively small; it is crowded between the canine and the second premolar $\left(\mathrm{pm}_{4}\right), \mathrm{m}_{1}$ and $\mathrm{m}_{2}$ are subequal in size, $\mathrm{m}_{3}$ has the talonid only slightly reduced. In Baluchistan, it was collected at 1108 meters (3600 feet) at the junction of Razhai \& Sichk Rivers (BMNH). In Iran, it was reportedly common in the town of Ahwaz (at an altitude of 68 meters: 220 feet) (BMNH). In Oman, it was found secreted in the walls of ruined buildings, isolated in semi-desert terrain (Harrison and Bates, 1991). In Afghanistan, three female specimens were collected at Lindberg's Cave, 25 miles north of Jalalabad: a further 23 specimens of both sexes were collected at an altitude of 738 meters (2400 feet) miles north of Jalalabad and a single female specimen from 862 meters (2800 feet) at Laghman.

\section{Discussion:}

Bats are a very poorly studied group of mammals in Pakistan. In the current study, we studied bats of Bajaur Agency, FATA region of Pakistan. The genetic identification and phylogenetic analysis are an obscured issue in chiropteran taxonomy as no molecular record for bats is available in Pakistan. This is the first attempt to describe the genetics of Rhyneptesicus nasutus from Pakistan. The study area is a hilly area which is not easily modified as compared to plain areas for construction activities that is why these flying creatures i.e., bats are surviving in these areas easily. Due to the non-availability of taxonomic position and data about the genus Rhyneptesicus, the data we collected during this work leads us to draw any conclusions about this genus. We captured different bats species from the study area. But here we just presented the Rhyneptesicus nasutus species. The previous records of Rhyneptesicus nasutus. Sind Serotine bat Vesperugo (Vesperus) nasutus (Dobson, 1877: 311) has been reported from Shikarpur, Sind, Pakistan and according to Blanford, 1888-91 type locality should be a little east of Rohri' [21] but the recent record from Bajaur agency FATA, Pakistan highlights the range extension of Sindh bat as this bat species has not been reported by anyone from this area. This report of Rhyneptesicus from Bajaur Agency might be by its migration from Afghanistan area or it may be local resident in Bajaur. Here, we will also highlight the difference in weather conditions of Bajaur Agency which is the hilly area while the Shikarpur, Sind, is a plain area where it was reported by Blanford, 1888-91. It also suggests that a detailed study on the comparison of ecological aspects should be conducted for further conservation action plans of this species.

No complete record for bats in Pakistan is available right now. Currently, some people are involving in research work about taxonomic and phylogenetic studies of bats. In the future, hopefully, enough data will be available to cover the exact taxonomic positions of various bat species from Pakistan. Juste et al. (2013) reassigned this taxon to the genus Rhyneptesicus Bianchi, 1917 based on molecular phylogenetics [8]. Four subspecies - R. n. nasutus (Southwest Pakistan, Afghanistan, and Southeast Iran), R. n. matschiei (Southwest Arabia), R. n. pellucens (Iran and Iraq), and R. n. batinensis (Eastern Arabia including Oman and Saudi Arabia), are recognized [8, 22].

Genetic markers like mtDNA and nuDNA describe a geographic and genetic relatedness for discontinuous distribution of the genus Rhyneptesicus. The taxonomic reconstruction of nasutus samples from Iran 
which are close to Pakistan validates the subspecies recognition [8] hence this study also confirms its presence by range extension and validation by molecular marker (cytochrome $b$ gene). Current molecular investigations have placed Eptesicus in tribe Nycticeini, separating it from pipistrelles [23]. For phylogenetic reconstruction, Genbank Accession Numbers of Rhyneptesicus species belonging to Iran were retrieved (FJ841981, FJ841980, EU786840, EU786839), from Oman (KF019042, KF019043, KF019044, KF019041, KF019040), from Yemen (KF019057, KF019056), from Germany (AF376836), from China (MG570068, EU786841), from Laos (EU786849) and from Patagonia (MK429705, MK429702, MK429700). While a vampire bat species Desmodus routundus (KU938397) was used as an outgroup in this phylogenetic reconstruction. The genetic divergence of these Rhyneptesicus species is given in table 3.

The genus Rhyneptesicus has a worldwide distribution and high diversity, and hence represents a tangled taxonomic puzzle among mammals. The status of this species is Least Concern as it has a widespread distribution and shows tolerance for modified habitats. So, it is unlikely to decline fast enough to categorize it as a threatened taxon. The distribution record of Rhyneptesicus nasutus is wide and patchy. It has been reported from Arabian Peninsula to western South Asia, recorded from Oman, Saudi Arabia, Yemen, United Arab Emirates (UAE), Qatar, Kuwait, southeastern Iran, and southern Iraq. From South Asia, it has been reported from Afghanistan and Pakistan, but from the territorial boundary of Pakistan, it is just reported from Baluchistan and Sind [9, 24, 25]. However, the new record for range extension of Rhyneptesicus nasutus is reported from Bajaur Agency, FATA, Pakistan.

The distributional record of Rhyneptesicus nasutus in Baluchistan (Seistan) is more or less continuous while in Afghanistan (Jalalabad valley) its occurrence is $700-800 \mathrm{~km}$ away to the nearest record of central Pakistan [9]. The distributional range of the Eptesicus is variable in different geographical areas depicts its adaptability to different geographically climatic ranges. Conversely, in the Middle East, the occurrence of Rhyneptesicus nasutus has been reported in a mosaic of isolated patches as compared to in a continuous belt $[26,27]$, this might be the case for its distributional range (Province Sindh and Baluchistan and then in the mountainous area of Bajaur Agency) in Pakistan distribution in central Pakistan represents another such patch; Bates \& Harrison (1997) summarized three records from central Baluchistan (Kharan, Rajbar, a junction of the Razhai and Sichk rivers; [9, 28], one from northern Sindh (near Rohri; (Blanford, 1898) and current study explores the identification and the range extension to northern Pakistan. Where an extensive survey should be conducted to explore more roost sites and population dynamics of Rhyneptesicus.

It is summarized that the effects of climate change on the range extension of Rhyneptesicus may be primarily determined by the weather consequences on the habitat requirements and physiological tolerances of the species under study. Here, in the case of Rhyneptesicus nasutus evolution in ecologically different environment of Bajaur Agency, Pakistan may be due to variable environmental conditions as compared to its prior occurrence in other regions of the country, i.e., Baluchistan and Sind province. The data obtained during this study is very significant as no record about phylogenetic analysis of bats is available in Pakistan. 
This study describes the comparison of cytochrome b sequences for Rhyneptesicus species from Pakistan, Iran, Oman, Germany, Laos, Yemen, China, and Patagonia to access the genetic divergence and evolutionary analysis among these localities of the world. The distribution and divergence in different parts of the world suggest that Rhyneptesicus species have evolved and spread in various localities as suggested by bootstrap values of more than $60 \%$. The close cladistic relationship of Pakistani and Iranian Rhyneptesicus specimens suggests that they share a common ancestry as compared to the others reported from the world. No data of cytochrome b from the Afghanistan region is available so we can not infer any cladistic relationship of Pakistani Rhyneptesicus specimens with Afghanistan's specimens.

Bat populations appear to be declining presumably in response to human-induced environmental stresses like habitat destruction and fragmentation, disturbance to caves, depletion of food resources, overhunting for bushmeat and persecution, increased use of pesticides, infectious disease, and wind energy turbines. As bats are among the most overlooked despite their economical and ecological importance, their conservation is mandatory. An extensive study is recommended to explore the distribution range and highlight the significance of bats throughout the territorial limits of Pakistan.

\section{Conclusion}

Sindh bat has a limited geographic range. The distributional range of this species is not thoroughly explored within the territorial limits of Pakistan. In Pakistan, it has only been reported from Sindh and Baluchistan. The present record of range extension of Rhyneptesicus nasutus is reported for the first time from the FATA region of Pakistan-based both morphological characteristic and genetic analyses

(cytochrome b). An extensive study with other molecular markers is recommended throughout the country so that the findings of the current study may be supported.

\section{Declarations}

Animals' Ethical Treatment: The author(s) declares that the animals used in this research work were handled with ethical standards for animal care and use in research approved by Society for Prevention of Cruelty to Animals (SPCA, University of Veterinary and Animal Sciences, Lahore, Pakistan.

Conflicts of Interests: The authors declare no conflict of interest with anyone.

Funding Resources: No funding was received from anybody. All the expenditures for research work were supported by the authors.

\section{References}

1. Agosti D (2003) Encyclopedia of life: should species description equal gene sequence? Trends Ecol Evol 18(6):273

2. Burgin CJ et al (2018) How many species of mammals are there? J Mammal 99(1):1-14 
3. Boyles JG et al (2011) Economic importance of bats in agriculture. Science 332(6025):41-42

4. Kasso M, Balakrishnan M, Ecological and economic importance of bats (Order Chiroptera). International Scholarly Research Notices (2013) 2013

5. Bickford D et al (2007) Cryptic species as a window on diversity and conservation. Trends Ecol Evol 22(3):148-155

6. Wilson DE, Reeder DM (2005) Mammal species of the world: a taxonomic and geographic reference. JHU Press

7. Clare EL (2011) Cryptic species? Patterns of maternal and paternal gene flow in eight Neotropical bats. PLoS One 6(7):e21460

8. Juste $\mathrm{J}$ et al (2013) Phylogeny and systematics of O Id W orld serotine bats (genus E ptesicus, V espertilionidae, C hiroptera): an integrative approach. Zoolog Scr 42(5):441-457

9. Bates P, Harrison D (1998) Bats of the Indian subcontinent. Biodivers Conserv 7(10):1383-1386

10. List, I.R., The IUCN red list of threatened species. Di sponí vel em: $<$ http://www. iucn red list. org/info/cat e go ries_cri te ria2001. html>. Aces so em, 2004. 12.

11. Benda P, Gaisler J (2015) Bats (Mammalia: Chiroptera) of the Eastern Mediterranean and Middle East. Part 12. Bat fauna of Afghanistan: revision of distribution and taxonomy. Acta Societatis Zoologicae Bohemicae 79:267-458

12. Francis $\mathrm{CM}$ et al (2010) The role of DNA barcodes in understanding and conservation of mammal diversity in Southeast Asia. PloS one 5(9):e12575

13. Ashwani K, Singh Y, Prasad G (2009) Cytochrome-b gene based PCR for identification and differentiation of cooked meat of sheep, goat, cattle, pig and poultry. Haryana Veterinarian 48:53-57

14. Zarringhabaie GE, Pirany N, Javanmard A (2011) Molecular traceability of the species origin of meats using multiplex PCR. Afr J Biotech 10(73):16461-16465

15. Roberts TJ (1977) The mammals of Pakistan. E. Benn

16. Hoelzel A, Green A, Analysis of population-level variation by sequencing PCR-amplified DNA. Molecular genetic analysis of populations: a practical approach (1992) p. 159-187

17. Kocher TD et al., Dynamics of mitochondrial DNA evolution in animals: amplification and sequencing with conserved primers. Proceedings of the National Academy of Sciences, 1989. 86(16): p. 61966200

18. Sanger F, Nicklen $S$, Coulson AR, DNA sequencing with chain-terminating inhibitors. Proceedings of the national academy of sciences (1977) 74(12): p. 5463-5467

19. Pty T, Ltd. Chromas Lite Software. 2018

20. Kumar $S$ et al (2018) MEGA X: molecular evolutionary genetics analysis across computing platforms. Molecular biology evolution 35(6):1547-1549

21. Blanford WT, The Fauna of British India: Including Ceylon and Burma. Vol. 4. 1898: Taylor \& Francis

22. Benda P, Reiter A, On the occurrence of Eptesicus bobrinskoi in the Middle East (Chiroptera: Vespertilionidae). Lynx (NS) (2006) 37: p. 23-44 
23. Hoofer SR, Van Den Bussche RA, Horáček I (2006) Generic status of the American pipistrelles (Vespertilionidae) with description of a new genus. Journal of mammalogy 87(5):981-992

24. Molur S et al. Status of South Asian Chiroptera. in Conservation Action Management Plan (CAMP) Workshop Report, Zoo Outreach Organisation, 320pp. 2002

25. Srinivasulu $C$ et al (2019) Integrated approaches to identifying cryptic bat species in areas of high endemism: The case of Rhinolophus andamanensis in the Andaman Islands. PloS one 14(10):e0213562

26. Benda P et al., Noteworthy records of bats from Yemen with description of a new species from Socotra. Hystrix, the Italian Journal of Mammalogy, 2010. 22(1)

27. Benda P, Vallo P (2012) New look on the geographical variation in Rhinolophus clivosus with description of a new horseshoe bat species from Cyrenaica, Libya. Vespertilio 16:69-96

28. Roberts T, The mammals of Pakistan (revised ed.) Oxford University Press. Karachi, Pakistan (1997) p. 525

\section{Tables}

Table 1 


\begin{tabular}{|lll|}
\hline Body Parameters & \multicolumn{2}{c|}{ Species understudy } \\
\cline { 2 - 3 } & Mean & Sind Serotine Bat (Rhyneptesicus nasutus) \\
\cline { 2 - 3 } & & \\
\hline Head and Body length & 44.3 & $40.0-46.0$ \\
\hline Tail length & 43.4 & $38.0-46.0$ \\
\hline Hindfoot length & 7.3 & $7.0-8.0$ \\
\hline Forearm length & 35.7 & $35.4-36.9$ \\
\hline $\mathbf{5}^{\text {th }}$ Metacarpal Length & 33.2 & $31.7-34.4$ \\
\hline 4 $^{\text {th }}$ Metacarpal Length & 34.7 & $33.7-35.7$ \\
\hline 3 $^{\text {rd }}$ Metacarpal Length & 35.3 & $34.1-36.6$ \\
\hline Ear length (EL) & 13.2 & $12.5-14.0$ \\
\hline Greatest Length of Skull (GTL) & 13.1 & $12.8-13.4$ \\
\hline Condylo-canine Length (CCL) & 12.0 & $11.7-12.2$ \\
\hline Zygomatic Breadth (ZB) & 8.6 & $8.4-8.8$ \\
\hline Breadth of the Braincase (BB) & 6.2 & $6.2-6.3$ \\
\hline Posteriorbital Constriction (PC) & 3.0 & $2.9-3.1$ \\
\hline Maxillary Toothrow (CM ${ }^{3}$ ) & 4.6 & $4.4-4.8$ \\
\hline Mandibular Toothrow (CM & 5.0 & $4.8-5.1$ \\
\hline Mandible Length (M) & 9.3 & $8.6-9.6$ \\
\hline maxillary width at M ${ }^{3}\left(M^{3}\right.$-M $\left.{ }^{3}\right)$ & 5.8 & $5.6-5.9$ \\
\hline
\end{tabular}

Tables 2 and 3 are not available with this version.

\section{Figures}


A

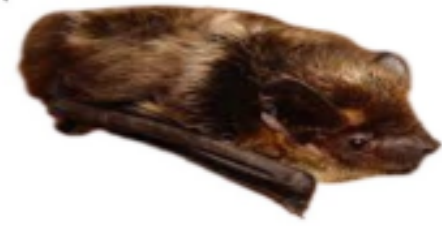

c

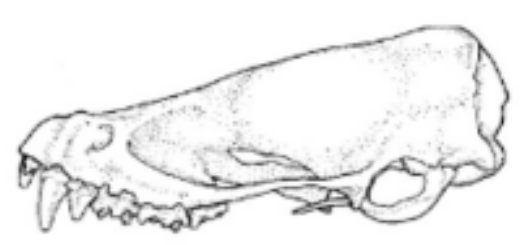

B

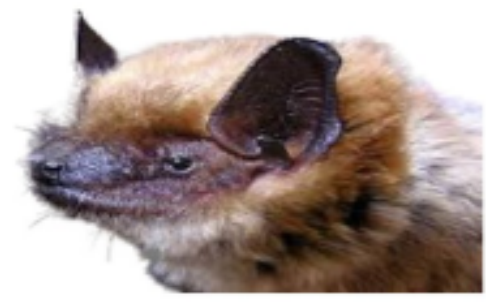

D

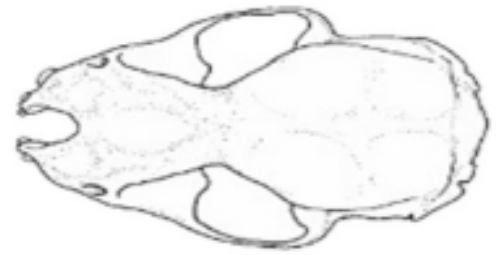

Figure 1

Morphological characteristics of Sindh Bat (Rhyneptesicus nasutus) from Bajaur Agency, FATA, Pakistan. $A \& B$ external morphology, $C=$ lateral view of skull $D=$ dorsal view of skull of Eptesicus nasutus.

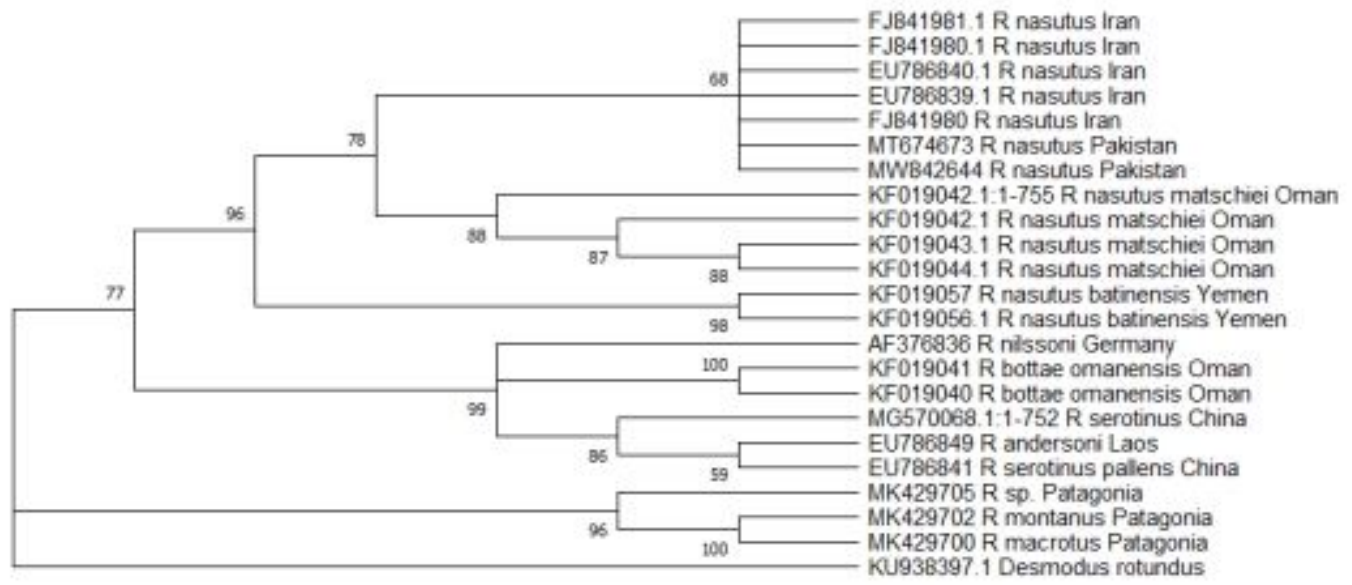

Figure 2

Phylogenetic reconstruction of Rhyneptesicus nasutus from FATA, Pakistan, where the samples from Pakistan are highlighted. Numbers at each node represent the bootstrap cutoff value. 


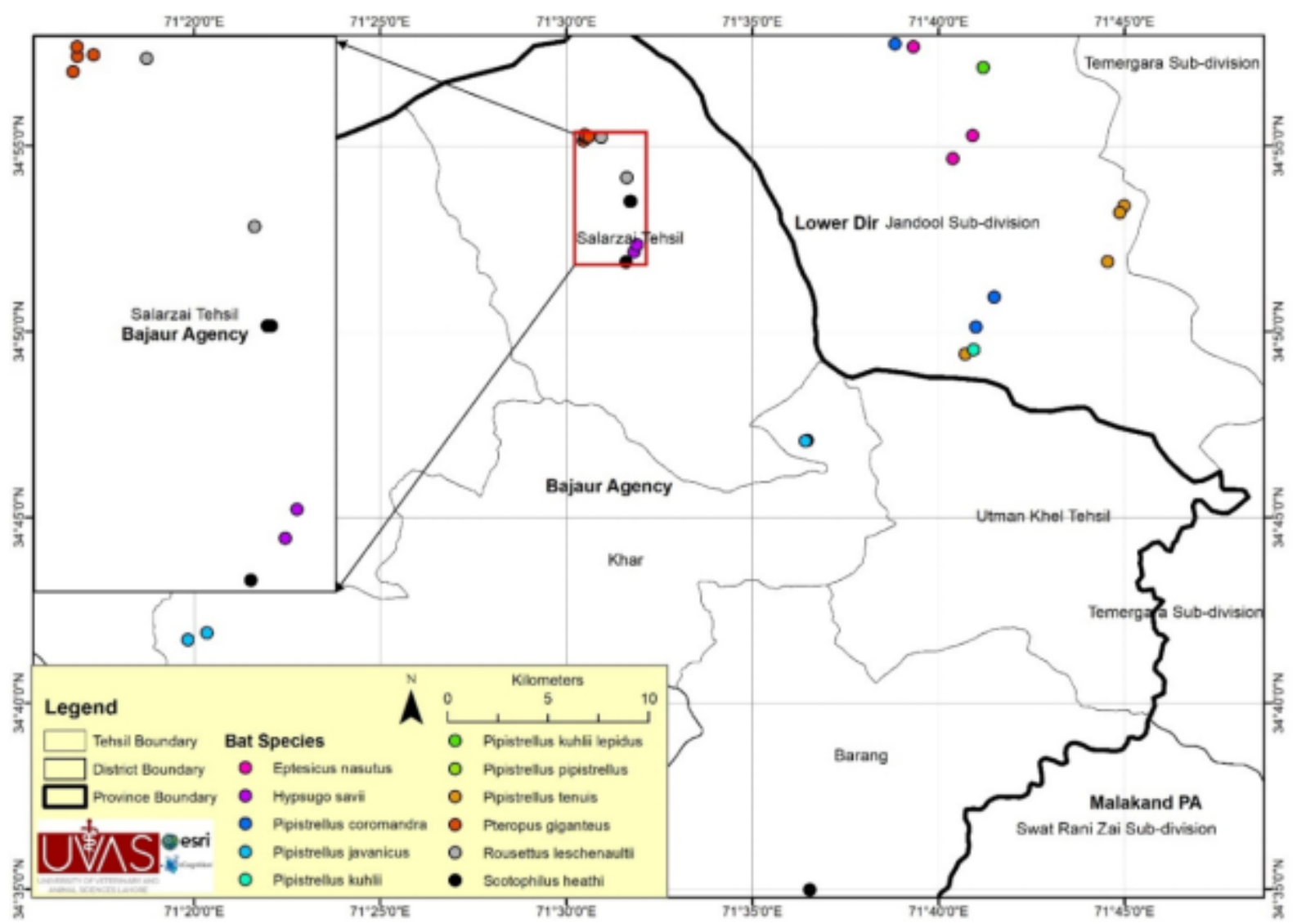

Figure 3

The study area of Bajaur Agency, FATA, Pakistan depicting the chiropteran diversity and distribution. 